\title{
José Manuel Estrada (1842-1894) y su obra histórica en la Argentina de las décadas de 1860 y $1870^{*}$
}

\author{
The historical work of Jose Manuel Estrada (1842-1894) in Argentina in \\ the decades of the 1860 s and 1870 s
}

\author{
Paula Bruno \\ pbruno@conicet.gov.ar \\ Investigadora \\ Universidad de Buenos Aires \\ 25 de mayo $221,2^{\circ}$ piso \\ 1002 - Buenos Aires \\ Argentina
}

\begin{abstract}
Resumen
En este artículo se analiza la trayectoria pública e intelectual del argentino José Manuel Estrada (1842-1894) como historiador entre las décadas de 1860 y 1870 . Para ello se repasan en primer lugar las obras que, aunque parcialmente, se han detenido en esa faceta del letrado. Luego se examinan los principales problemas que guiaron sus indagaciones en el pasado: los legados del período colonial y de la revolución, las relaciones entre caudillos y sociedad, la centralización del poder, el estado de la campaña y las formas de escribir historia. Son presentadas, asimismo, algunas evaluaciones de contemporáneos sobre la obra de Estrada y se hace hincapié en las particularidades de ese corpus que pueden explicar la poca atención que recibió posteriormente, a pesar de haber sido valorado en su tiempo.
\end{abstract}

\section{Palabras clave}

Historia de la historiografía; Siglo XIX; Argentina.

\begin{abstract}
This article analyzes the public and intellectual trajectory of Argentine author José Manuel Estrada (1842-1894) as a historian in the decades of the 1860 s and 1870s. It first examines the texts that, albeit partially, have looked into this facet of his work. Then, it considers the main problems that guided his inquiries into the past: the legacies of the colonial period and of the revolution, the bonds between caudillos and the society, the centralization of power, the state of the countryside and the ways of writing history. The article also presents the evaluations of some of Estrada's contemporaries regarding his work, and emphasizes the particularities of his writings that may explain the lack of attention they have received subsequently, despite the fact that they were valued in their time.
\end{abstract}

\section{Keywords}

History of historiography; $19^{\text {th }}$ century; Argentina.

\author{
Recibido el: 14/7/2014
}

Aprobado el: 23/10/2014

\footnotetext{
* Investigación financiada por el Consejo Nacional de Investigaciones Científicas y Técnicas - CONICET.
} 
José Manuel Estrada ${ }^{1}$ nació en Buenos Aires en 1842 y falleció en Asunción, Paraguay, en 1894. Fue miembro de una familia con una historia enraizada tempranamente en la ciudad de Buenos Aires: biznieto del Virrey Santiago de Liniers, hijo de José Manuel de Estrada Barquín y de Rosa Perichón de Vandeuil y Liniers y familiar de otras figuras destacadas de la cultura argentina, como Santiago y Ángel Estrada. Su educación formal, que finalizó en 1858, tuvo lugar en el Colegio de San Francisco, donde recibió una sólida y completa formación humanística. Nunca circuló, en tanto estudiante, por las aulas universitarias.

Como periodista, sus escritos ocuparon las columnas de diversos órganos y fue director y fundador de los periódicos El argentino (1873-1874), La unión (1882-1889) y de la Revista argentina (1868-1872 y $1880-1882)$.

Como hombre político, ocupó diversos cargos e intervino en debates centrales de la Argentina post-Caseros. Fue parte, desde 1871, de la Convención Provincial, diputado de la Legislatura entre 1873 y 1876 y diputado por la Provincia de Buenos Aires entre 1886 y 1889. Participó en los mítines de 1890 y formó parte de la Unión Cívica. Fue subsecretario de Relaciones Exteriores durante la presidencia de Domingo Faustino Sarmiento y, años más tarde, ocupó durante el gobierno de Luis Sáenz Peña el cargo de ministro plenipotenciario en el Paraguay.

Estrada hizo despuntar muy tempranamente su veta polémica. A comienzos de la década de 1860 rebatió a Gustavo Minelli y Francisco Bilbao, quienes habían puesto en duda algunos principios explicativos de la religión católica. Más adelante, desde La unión, voz de los católicos en el marco de las reformas laicas de la década de 1880 , devino polemista de pluma incansable.

Como hombre del catolicismo argentino, su labor fue comprometida. Desde sus años juveniles dictó varias conferencias sobre religión, teología e historia en diversos espacios de reunión del catolicismo y por largos años fue secretario de la Conferencia Vicentina de la Parroquia San Ignacio. En la década de 1880 fundó el ya mencionado periódico La unión, realizó campañas por el interior del país y Uruguay para organizar a los adeptos de la causa católica, presidió la Asociación Católica - por él mismo reorganizada- y el Comité Central del partido Unión Católica Argentina.

Su performance como educador fue notable. En 1866 y 1868 dictó famosas lecciones de historia argentina en la Escuela Normal. Durante la presidencia de Sarmiento fue nombrado jefe del Departamento General de Escuelas y presidente del Congreso de Instrucción Pública y, en 1874, fue director de Escuelas Normales. En el Colegio Nacional de Buenos Aires fue docente de las asignaturas Instrucción Cívica e Historia Argentina y rector entre 1876 y 1883. Se desempeñó asimismo como catedrático de Derecho Constitucional y Administrativo en la Facultad de Derecho y Ciencias Sociales de la Universidad de Buenos Aires y el Congreso Pedagógico Nacional de 1882 lo tuvo como uno de sus vicepresidentes.

\footnotetext{
${ }_{1}^{1}$ Para un desarrollo exhaustivo de la trayectoria vital e intelectual de Estrada me permito remitir a BRUNO 2011. Por motivos de espacio, no puede presentarse aquí extensamente dicha trayectoria y se ha optado por una semblanza en la que se trazan características generales de su figura.
} 
Como promotor cultural, Estrada fue fundador, junto a Lucio V. Mansilla, del Círculo Literario (1864-1866) (BRUNO 2014); participó, a comienzos de la década de 1860, de las tertulias de la Librería del Colegio, de Paul Mortá; y asistió a diversos eventos de sociabilidad intelectual. Fue traductor de Examen crítico de la "Vida de Jesús" de M. Renan, de Carlos Emilio Freppel, y de varios textos en italiano de los padres Gervasoni y Cattaneo. Junto con su hermano Santiago tradujo Los miserables de Víctor Hugo y realizó una comentada y reconocida edición de María, de Jorge Isaacs, acompañada por los poemas del mismo autor.

Pese a ser un polígloto y un personaje de múltiples mundos (BRUNO 2011), en este artículo se analiza, en particular, el rol de Estrada como historiador. En 1865 escribió su Ensayo histórico sobre la revolución de los comuneros del Paraguay y su pasión por la historia se convirtió en uno de los pilares de su trayectoria pública y docente. Dictó numerosas conferencias y clases de historia argentina que fueron editadas en varios volúmenes: Fragmentos históricos (1866, publicados póstumamente), ${ }^{2}$ Lecciones sobre la historia de la República Argentina (1868) y La política liberal bajo la tiranía de Rosas (1873). Existen, además, consideraciones históricas en varios de sus artículos y conferencias. Sin embargo, como se verá en el siguiente apartado, ese perfil de Estrada ha sido fragmentariamente explorado.

\section{José Manuel Estrada como historiador}

En el marco de la primera obra sobre la historia de la historiografía argentina, Rómulo Carbia reconoce a Estrada como el fundador de una corriente historiográfica poco fructífera y sin un método: la "historiografía filosofante" (dentro de la cual también menciona a Lucio V. López). Así, el tratamiento de fuentes y los modelos explicativos habrían quedado subsumidos, en su obra, a una filosofía ordenadora de la historia, que avanzó en detrimento de un aparato erudito y una clara organización de argumentos (CARBIA 1939, p. 139-147). Estrada estaría así en la vereda opuesta a la de la "escuela erudita", tendencia en la que, como es sabido, Carbia ancló una tradición de continuidad y legitimidad que ligaba a los miembros de la Nueva Escuela Histórica con el ilustre ancestro Bartolomé Mitre (PAGANO; GALANTE 1993).

Ya para fines de la década de 1950, Raúl Orgaz retomaba en parte esa definición y mencionaba a Estrada como el pionero de la "historia filosofante" o la "historiosofía" argentina (ORGAZ 1960, p. 23, 57 y 59). Contemporáneamente, Barager también lo inscribió dentro de un grupo opuesto a la escuela erudita, conformado por Alejandro Magariño Cervantes, considerado el fundador de esa contraescuela, Lucio V. López y Mariano Pelliza. A diferencia de Carbia, sin embargo, Barager señala que esos escritores adhirieron a la mirada general de Bartolomé Mitre, pero se distinguieron de él por su énfasis en el punto de vista subjetivo. Por otro lado, ese autor señala que la obra de Estrada 
respondía a formas ancladas en la oralidad (discursos, conferencias, lecciones, intervenciones públicas) y por eso lo caracteriza como un "historiador orador" (BARAGER 1959, p. 593).

Por su parte, promediando la década de 1970, Miguel Ángel Scenna ubicaba a Estrada en "la segunda generación" de historiadores argentinos, integrada por Mariano Pelliza, Paul Groussac, Adolfo Saldías, Clemente Fregeiro y Ernesto Quesada, cuya originalidad es desdibujada cuando el autor señala que su principal característica fue seguir los pasos de la generación anterior (SCENNA 1972). Scenna suma a Estrada en las filas de la escuela filosófica y guizotiana y lo compara con Vicente Fidel López, pero precisando que contó con menos talento que este. Sostiene, además, la posibilidad de que Estrada mismo no se considerara historiador, sino solo educador histórico.

Más allá de esos panoramas generales, algunas pocas contribuciones se detienen específicamente en las obras históricas de Estrada. Por ejemplo, Enrique de Gandía se refiere a ellas como piezas injustamente desconocidas y rescata los contenidos y el plan del Ensayo sobre la revolución de los comuneros del Paraguay. El autor traza una genealogía de desacreditadores del texto, inaugurada por Pedro Goyena y continuada por Juan Garro y otros biógrafos de Estrada y argumenta que esa campaña desprestigiadora habría estado dada por las observaciones críticas sobre la Compañía de Jesús manifestadas por Estrada. De Gandía destaca, además, la labor documental de Estrada y reivindica las Lecciones sobre la historia de la República Argentina como "un punto de partida, un modelo admirable", "uno de nuestros primeros ensayos de historia patria" y "manuales de historia integral" (DE GANDÍA 1943, p. 145, 149 y 153; 1962).

Otro breve aporte de Pedro Murúa define la manera de hacer historia de Estrada como la de un "Michelet con resonancias criollas" (MURUA 1942, p. 290). Justifica, además, sus formas rudimentarias de documentarse, destacando que, en la época, no se habían consolidado aún las escuelas históricas que hacían de la erudición y la crítica documental su quintaesencia (se refiere a la heurística alemana).

Ya en la década de 1960, un artículo de Rosa Zuluaga centrado en Estrada se encarga de señalar que Lecciones de historia de la República Argentina y La política liberal bajo la tiranía de Rosas son las dos obras que "encierran el primer intento de una síntesis filosófica del pasado nacional, formulada desde la perspectiva típica del liberalismo democrático de su época" (ZULUAGA 19601961, p. 229). Según esa autora, Estrada habría sido el primer "historiador oficial", escritor de la versión del pasado compartida por la generación que ocupó el escenario público luego de Caseros (ZULUAGA 1960-1961, p. 253).

Otros textos presentan señalamientos generales acerca de alguno de los escritos históricos de Estrada o de alguna de sus ideas, pero sin pretensiones interpretativas sobre su producción en el largo plazo. Es el caso de contribuciones en las que, por ejemplo, se aborda el tema de la historia de las misiones jesuíticas (MARI 2005) o se plantea algún tipo de enfoque panorámico sobre las ideas de revolución vigentes en los estudios históricos sobre América Latina (LINARES QUINTANA 1951). 
Entre la década de 1970 y la actualidad, no se encuentran estudios que focalicen su mirada en la obra de Estrada. De hecho, aunque una cantidad significativa de sus páginas históricas están destinadas a la época de Rosas, estudios que centran la atención en ese tópico de la historia nacional no se detienen en su obra (CLEMENTI 1970; QUATTROCCHI-WOISSON 1998).

Por su parte, dentro del marco más específico de la historiografía del campo católico argentino, la obra de Estrada fue más bien minimizada. Su primer biógrafo, Juan Garro, criticó severamente el Ensayo sobre la revolución de los comuneros y lo consideró obra de una "exaltada imaginación juvenil" que condujo a su autor a magnificar "aquella revolución local asignándole móviles grandiosos y proyecciones trascendentales que los hechos no confirmaron" (GARRO 1899, p. XVIII). Además, señaló que, aunque hubo en Estrada un "historiador concienzudo y brillante", sus opiniones negativas sobre el pasado colonial y la Compañía de Jesús fueron desmesuradas (GARRO 1899, p. XXIII). En otras biografías, que siempre retoman las apreciaciones de este último autor como punto de partida, la obra histórica de Estrada es también considerada poco representativa y casi no recibe atención (DE PATAGONES 1938; TESSI 1928). El Estrada historiador, en suma, no se ha convertido en una figura recuperable para quienes vindican al Estrada católico. Paradójicamente, en la obra panorámica más reciente sobre historiografía argentina, Estrada es considerado un exponente central de una incipiente historiografía católica argentina (DEVOTO; PAGANO 2009, p. 30).

\section{Estrada y su obra histórica: períodos, tópicos y problemas}

Puede que el interés histórico de José Manuel Estrada haya despuntado cuando escribió una monografía sobre Cristóbal Colón que fue premiada en 1858 por el Liceo Literario. Ya para comienzos de 1862, además, dictó varias conferencias históricas en la Sociedad de San Francisco Javier. ${ }^{3}$ Pero si esas incursiones en los terrenos del pasado depositaron su atención en temas universales y portaron consigo un tono general, más cercano a la "divulgación", para comienzos de la década de 1860, Estrada se interesó de manera decidida por la historia nacional.

En el marco de La revista de Buenos Aires, empresa editorial que acompañó de cerca su carrera ascendente, apareció en 1863 un cuidadoso estudio sobre las ediciones existentes de la obra del padre Guevara (ESTRADA 1863). Se trata de un trabajo erudito sobre cómo realizar ediciones documentales y sobre su utilidad para reconstruir el pasado. Además de criticar las ediciones del padre Guevara realizadas por Pedro de Angelis y Félix de Azara y de señalar detalladamente alteraciones, el joven devenido casi metodólogo avant la lettre manifestó allí sus preocupaciones por el estado de los documentos y los repositorios del país. Además, postuló por primera vez sus ideas acerca de la utilidad de la historia y esbozó un doble programa: reconstruir el pasado por medio del tratamiento sistemático de fuentes y cumplir con una misión 
patriótica. Desde su perspectiva, la historia podía movilizar "el espíritu del país, que debe tener hambre de conocerse a sí mismo, para aprender a amarse. No hay prédica más eficaz de amor a la patria, que la historia bien estudiada" (ESTRADA 1863, p. 156). ${ }^{4}$

Luego de la aceptación generada por la lectura de fragmentos de su obra en el Círculo Literario (BRUNO 2014), Estrada publicó, en 1865, Ensayo histórico sobre la revolución de los comuneros del Paraguay en el siglo XVIII. ${ }^{5}$ En el momento de aparición de ese volumen, su autor ocupaba el cargo de secretario de la Comisión Sanitaria de Hospitales Militares, presidida por Juan Montes de Oca, y seguía atentamente los ritmos de la guerra de la Triple Alianza. En esos años participó también en el diario de Bartolomé Mitre, La nación argentina, justamente en el momento en el que el presidente de la Argentina se convirtió en la figura central en tiempos del conflicto.

En las interpretaciones de Estrada, Paraguay era una nación enemiga y escribir su historia asumía una contemporaneidad indiscutida. Estrada asumió esa urgencia combinando su tarea periodística con su labor como historiador. Los antecedentes narrados en los capítulos del ensayo sobre la revolución de los comuneros permitían conocer "el terreno en que vino a plantear sus trabajos de zapa y corrupción el Dictador perpetuo, y las esperanzas que la marcha ulterior impresa a la política ha defraudado para el mismo pueblo y para la América liberal" (ESTRADA 1899, p. 352), mientras que el apéndice que narraba la historia del Paraguay y su decadencia hasta 1865 propiciaba una comprensión particular del conflicto.

El entusiasmo que le generó la contienda es contundente en ese apéndice. A tono con otras lecturas contemporáneas sobre la Guerra del Paraguay (BREZZO 2006), Estrada planteó la guerra en términos duales de civilización-barbarie, tiranía-libertad:

La guerra [...] está trabada entre la civilización y la barbarie. Representa la lucha de todos los pueblos del Plata en defensa propia y en prosecución de un objetivo inspirado por la generosidad del corazón democrático, que palpita vigorosamente en las tres naciones aliadas (ESTRADA 1899, p. 351).

En el registro histórico del libro, Estrada recorre la historia colonial y juzga negativamente a la monarquía española y a la Compañía de Jesús por sus acciones centralizadoras. Los levantamientos comuneros son narrados por medio de personajes históricos que considera centrales: el índice se organiza sobre los nombres de Don José de Ábalos, Don Diego de los Reyes, Don Tomás de Cárdenas, Don José de Antequera, Don Fernando Mompo, Don Ignacio Sorotea

\footnotetext{
${ }^{4}$ Cabe destacar que, aunque algunas de las intervenciones de Estrada estaban en sintonía con discusiones que mantenían sus contemporáneos, él no participó activamente en los debates centrales de esas décadas sobre metodología ni vinculados a los "mitos fundantes" de la nación y la nacionalidad. Para un análisis sobre el contexto de producción en el que se inscribe la obra de Estrada remito a DEVOTO; PAGANO 2009, p. 13-72 y EUJANIAN 2003, p. 17-42.

${ }_{5}^{5}$ Supuestamente, el contenido de este texto formaría parte de una más ambiciosa Historia de la provincia de Misiones, que nunca fue concretada. Pueden verse borradores de la obra en AGN/UCA, FDJME, Capítulo primero de la obra "Historia de la Provincia de Misiones", referido a la conquista de América. Signatura. Top: 3370. Folios: 570 a 593.
} 
y Barreyro, entre otros. Apunta que los comuneros "galvanizaron un pueblo aletargado para llevarlo a sofocar la voluntad vehementemente manifestada de otro pueblo viril, que reclamaba a todos los usurpadores del derecho una limosna de libertad y una migaja siquiera de justicia y decoro político" (ESTRADA 1899, p. 51). Encuentra en la revolución loables motivos: rescata que las ciudades (el poder local) se enfrentaron en la revolución a la injusticia de la monarquía (el poder centralizado). Se concentra, además, en la figura de los caudillos, preguntándose si ellos son manifestaciones naturales del pueblo o simples líderes políticos oportunistas. Esos interrogantes sobre las tensiones entre centralismo y localismo y los caudillos en relación con las fuerzas sociales atravesaron su lectura del pasado nacional en los años posteriores.

En relación con la concepción de historia de Estrada, en el mismo texto señalaba que era necesario contar el pasado con grandes trazos y con tono interpretativo: "abrazar los conjuntos, descuidando los detalles, y narrar sintéticamente los hechos para someterlos a juicio y discurrir sobre su carácter y significación" (ESTRADA 1899, p. VII). Quizás fue esa concepción histórica la que condujo a los autores de los textos historiográficos reseñados a caracterizar la obra de Estrada como filosofía de la historia. ${ }^{6}$

La recepción de ese ensayo entre sus contemporáneos fue amplia. Pedro Goyena describió el texto como fruto de un desmedido fervor juvenil (GOYENA 1965, p. 122). Aunque reconoció que el plan de la obra respondía "a todas las exigencias de un espíritu anheloso de información", criticó los excesos: "el señor Estrada exagera la importancia de los hechos que forman materia de su libro". A partir de ese argumento, señaló que Estrada le había dado demasiada centralidad a "un pueblo inculto que se levantaba estremecido por la atracción fascinadora de un caudillo (Fernando Mompo)" y definió el levantamiento como "sublevación de esclavos" (GOYENA 1965, p. 123). En un tono más elogioso, Nicolás Avellaneda y Bartolomé Mitre ${ }^{7}$ hicieron llegar sus felicitaciones al autor del Ensayo. Mitre no dudó en marcar su paternidad a la hora de hablar del Estrada historiador:

Siga Ud. adelante que suyo será el tiempo [...] Mi aplauso será el más sincero de todos, porque además de ser hijo de la amistad, se revelará en él la satisfacción propia de haber sido uno de los primeros que presentí el rico germen que encerraba su corazón y su cabeza. ${ }^{8}$

Aunque no se encuentran evidencias acerca de las opiniones de Mitre sobre el apéndice que Estrada sumó a su libro - conformado por la reescritura de sus artículos periodísticos de La nación argentina-, quizás la lectura sobre la guerra y su rol civilizador fue por él bien recibida. Desde la perspectiva del propio Estrada, su pluma había prestado un servicio al país en el contexto de la

\footnotetext{
${ }^{6}$ Para consideraciones sobre las posibilidades de desarrollo de ideas históricas en el siglo XIX puede verse PRADO 1999.

7 AGN/UCA, FDJME, Cuadernillo de copias de correspondencia de Nicolás Avellaneda y Bartolomé Mitre dirigida a José Manuel Estrada. Signatura. Top: 3366. Folios: 173 a 177, 1865.

8 AGN/UCA, FDJME, Carta de Bartolomé Mitre a José Manuel Estrada. Signatura. Top: 3366; Folio: 178, $15 / 06 / 1865$.
} 
Guerra del Paraguay: "podré no adquirir reputación literaria, pero conquistaré seguramente algo que debe estar más arriba en la conciencia del ciudadano: la satisfacción de haber cumplido; y porque este libro, bueno o malo, representa un esfuerzo en servicio de mi país" (ESTRADA 1899, p. X).

También en 1865 Estrada publicó traducciones de cartas de los padres Gervasoni y Cattaneo en la Revista de Buenos Aires. Los textos están precedidos por una carta-introducción destinada a Vicente Quesada. En ese escrito se muestra como un conocedor de los debates acerca del método histórico vigentes. Menciona las formas de pensar la historia de Thomas Macaulay en términos ejemplares (especialmente su forma de organizar el relato histórico en Historia de Inglaterra desde el advenimiento de Jaime II) y plantea programáticamente su forma de hacer historia:

el hombre serio que aspira a apoderarse de los secretos históricos de un pueblo, y dominar su genio y resolver los problemas de su destino (noble y altísimo objeto de la historia) debe explorar cuidadosamente sus rumbos, analizar los resortes de su vida y leer, por decirlo así, las pasiones que lo han perturbado, los vicios que lo tiranizaron, y las ideas que germinaban en su espíritu retemplando o relajando su nervio (ESTRADA 1865, p. 553). ${ }^{9}$

Esa propuesta, ya antes esbozada, guió a Estrada en su trabajo como historiador de la Argentina. Luego del estudio sobre los comuneros, abandonó el camino de la recopilación de documentos y se alejó cada vez más de las formas "mitristas" de hacer historia. Definió así un perfil de historiador que interpretaba las relaciones entre pasado, presente y porvenir en detrimento de un historiador erudito.

Gracias a su trabajo sobre los comuneros, Estrada fue convocado por Luis Peña, Director General de Escuelas, para dictar un curso de historia en la Escuela Normal de Buenos Aires. En la correspondencia intercambiada por ambos respecto de ese curso, Estrada señaló ejemplos de textos históricos que le resultaban útiles para pensar la forma de dictar sus lecciones (incluyó a François Guizot, Fréderic Ozanam, Edgard Quinet, Édouard Laboulaye) y propuso:

estudiar grandes grupos de hechos, el análisis de diversos estados sociales recorridos por la República, desde el descubrimiento hasta nuestros días, del espíritu que los ha precedido y de las consecuencias que han entrañado; estudiar decía el desarrollo de las ideas, de los principios y de la riqueza pública, terminando por el examen de la actualidad y los presentimientos del provenir. ${ }^{10}$

Con esas pretensiones en mente, dictó en 1866 sus lecciones. ${ }^{11}$ Los tópicos centrales de las conferencias fueron: los vicios "antidemocráticos" legados por la sociedad colonial y el poder centralizador de la monarquía española; las

\footnotetext{
${ }^{9}$ Las traducciones continuaron apareciendo hasta el Tomo XI de la revista y se reprodujeron en ESTRADA 1901. ${ }_{10}$ AGN/UCA, FDJME, Carta de José Manuel Estrada a Luis De La Peña; Signatura. Top: 3371. Folios: 1 y 2, $17 / 10 / 1865$.

${ }^{11}$ Existe una publicación póstuma de algunas de las veintiocho conferencias que dictó y que fueron seleccionadas por su hijo Alberto Estrada: ESTRADA 1901.
} 
potencialidades del poder municipal como base de la organización de una nación, la "tiranía" de Juan Manuel de Rosas y la Constitución de 1853, entre otros.

Otro grupo de lecciones estuvieron destinadas a repasar la historia desde 1492, deteniéndose en el virreinato. En esas conferencias sostuvo una mirada entusiasta ante los destinos históricos de Estados Unidos y la figura del pioneer. Cumplida su tarea, él mismo se percibió como un "laborioso obrero del progreso nacional" (ESTRADA 1901, p. 46). Este primer ciclo de conferencias fue excelentemente recibido por diferentes medios de circulación periódica. Rezaba La revista de Buenos Aires:

\begin{abstract}
El interés que inspiran sus serias investigaciones está justificado por la inmensa concurrencia que lo escucha [...] Estrada inicia con sus lecturas un nuevo rumbo a las ocupaciones serias de la juventud: sus lecciones obligan a meditar y a darse cuenta del origen y causas de males que nos trabajan, sembrando los buenos principios, con prescindencia del interés de partido que tan deslealmente ha falseado a veces lo que ha llamado historia (QUESADA 1866, p. 158 y 160).
\end{abstract}

Sin embargo, no fueron esas conferencias las destinadas a trascender sino las pronunciadas en la Escuela Normal en 1868 y publicadas primero en Revista argentina y luego en dos volúmenes como Lecciones de historia de la República Argentina. Estrada asumió una vez más la preparación de esas lecciones como un trabajo precursor: "la primera exposición científica de la generación democrática del pueblo argentino" (ESTRADA 1896a, p. VI). Las lecciones recorren la historia desde la conquista hasta la época de Juan Manuel Rosas. En cuanto a las fuentes, se encuentran referencias a los cronistas y a las Leyes de Indias, a los escritos del Deán Gregorio Funes, Juan Ignacio Gorriti, Esteban Echeverría, Domingo Faustino Sarmiento y Bartolomé Mitre, entre los más destacados; además de algunas referencias a diversos documentos oficiales (decretos, proclamas, oficios, actas, como las de la Asamblea de 1813 y las del Congreso de 1816) y fuentes periódicas (especialmente la Gaceta, para los tiempos de la revolución).

Estrada termina de condensar allí sus ideas sobre el despliegue histórico de estas tierras: el poder absoluto de la monarquía hispánica fue ilegítimo porque se dedicó a aplastar y destruir las libertades. La usurpación, la violencia, el fanatismo, las jerarquías obtusas, la enfeudación y la decadencia fundaron "a la sociedad argentina sobre una absoluta y múltiple negación de la libertad" (ESTRADA 1896a, p. 105). Pese a ese estéril cuadro, se sembraron las semillas de la nacionalidad argentina, que encontrarían un paulatino desenvolvimiento luego de la revolución de 1810, momento de inicio de "la verdadera historia de los pueblos" y del "desarrollo político y moral" (ESTRADA 1896a, p. 72).

A tono con los trabajos de publicistas de las décadas anteriores (WASSERMAN 2004; 2008) y con algunos de sus contemporáneos (EUJANIAN 2003; PRADO 1999), para Estrada los legados coloniales fueron difíciles de administrar en los procesos históricos argentinos; $y$, desde su perspectiva, dado que la revolución fue obra del pueblo, la anarquía se manifestó como una expresión 
de la democracia. Reaparece así una preocupación ya presente en el ensayo sobre los comuneros: ¿los caudillos eran la encarnación de una fuerza legítima? Ya en estas lecciones realiza una semblanza de Rosas en varios trazos: "lo vimos crecer a la sombra de los desórdenes y gracias a funestos errores de los partidos civilizados" (ESTRADA 1896b, p. 403-404); y señala que ese personaje representó a una fuerza social. Años más tarde retomó esas ideas en La política liberal bajo la tiranía de Rosas.

\section{La campaña: una maqueta de observación sociohistórica}

A lo largo de esos años, Estrada analizó el pasado nacional argentino con una pregunta rectora: ¿cómo encontrar un orden para la nación en el cual la política y la sociedad fueran dos esferas mutuamente acompasadas? Desde sus primeras lecciones históricas postuló que la revolución de mayo de 1810 había marcado un doble destino para la Argentina, ya que había sido una revolución política y a la vez social (ESTRADA 1917, p. 38; 1904). A partir de entonces, las relaciones entre política y sociedad condicionaron momentos problemáticos o armónicos para el país.

En esos encuentros y desencuentros entre la sociedad y la política, el rosismo fue un período histórico particular. A diferencia de quienes sugerían que el "tirano" era una emanación monstruosa, Estrada pensó en Rosas en términos de un "producto de la sociedad de su tiempo" que había sabido conciliar, tiránica pero efectivamente, las necesidades de la sociedad con los intereses políticos (ESTRADA 1903, p. 75). Ninguna de las experiencias desplegadas entre 1810 y fines de la década de 1820 había conseguido ese objetivo.

Ahora bien, ¿cómo recrear la alianza sociedad-política que el rosismo había conseguido pero bajo formas democráticas, civilizadas y ordenadas? En ese punto, Estrada señaló que Esteban Echeverría y los hombres de la "generación del 37" habían realizado un pronóstico errado. Habían creado una serie de proyectos nacionales a la sombra del odio al tirano y desde el lugar del discurso enemigo. Era necesario revisar esas propuestas para establecer de manera menos apasionada las prioridades y pensar en las lecciones del rosismo. A su vez, se imponía la necesidad de observar la realidad social argentina. Los proscriptos unitarios y los hombres del 37 no habían estado en condiciones de hacerlo (ESTRADA 1917, p. 324-339), pero la "nueva generación democrática" debía asumir esa observación de la sociedad como un mandato patriótico (ESTRADA 1896a, p. VI).

La tarea de los hombres que ocuparon el escenario post-Caseros era para Estrada doble: alcanzar la conciliación al interior de la arena política entre las facciones y reconstruir el lazo entre la esfera política y la social. Así,

derrocar a Rosas era nada. A lo sumo importaba remover un estorbo vivazmente arraigado por el terror y la corrupción, imperante por la fuerza que disciplinaba sobre una sociedad descompuesta. [...] su caída habilitaba al pueblo para continuar la elaboración revolucionaria en el fondo de la sociedad y en el terreno de las instituciones. Tal era la misión histórica de los hombres traídos al gobierno después de la batalla de 
Monte Caseros: purificar al país, adelantar su organización, restablecer y vigorizar la unidad de la patria (ESTRADA 1904, p. 40-41).

El año de 1852 habría generado un escenario desierto: "un tirano caído y un pueblo incompletamente rehecho para la libertad: una nacionalidad en vía de reorganizarse y ningún elemento positivo para constituirla" (ESTRADA 1904, p. 45). Urquiza, considerado "hombre educado en las tiendas de las montoneras y engreído por un largo ejercicio de la tiranía" (ESTRADA 1904, p. 45), no había estado a la altura de las exigencias de la conducción de ese proceso. Bartolomé Mitre, figura en la que Estrada depositó su confianza juvenil, había tratado de reconducir el proceso por medio de la guerra.

Como se ha sugerido, la fascinación de Estrada frente a la Guerra del Paraguay se tradujo en un respeto solemne por la figura de Mitre. El fervor bélico, sin embargo, fue breve y Estrada entendió que más que solucionar los problemas estructurales de la Argentina, la guerra los había postergado: la política y la sociedad continuaban siendo dos esferas escindidas luego del mandato de Mitre. ${ }^{12}$ Estrada cerró su ciclo de expectativas en el mitrismo con una reflexión: "el sable mutila, pero no regenera" (ESTRADA 1903, p. 94).

En el contexto de la candidatura de Domingo F. Sarmiento a la presidencia, Estrada planteó un giro hacia una solución destinada a perdurar en su ideario: era necesario un equilibrio entre "la moral y la democracia", fórmula en que encontraba la traducción del maridaje necesario entre la sociedad y la política (ESTRADA 1903, p. 74). Ese equilibrio, según él, podía llegar con la conducción de Sarmiento, menos propenso a guerrear y más volcado a diseñar programas de progreso social. ${ }^{13}$

Con ese principio en mente, durante las décadas de 1860 y 1870 , Estrada pensó los problemas de la Argentina a partir de un objeto-tópico: la campaña. ${ }^{14}$ Observándola en el largo plazo detectó principalmente tres desbarajustes. En primer lugar, la vida de sus habitantes dejaba en evidencia una desigualdad social estructural entre el campo y la ciudad (ESTRADA 1903, p. 87) que propició el surgimiento de caudillos. En segundo lugar, la centralización política y económica no atendía las demandas de los hombres de la campaña (ESTRADA 1903, p. 103).

La Argentina anhelada por Estrada debía dar respuesta a esos desequilibrios. Las soluciones que propuso variaron con el tiempo. Hacia 1868, encontraba la solución en la fórmula sarmientina: "educación para todos, educación común, educación igual, educación republicana" (ESTRADA 1903, p. 94). Esta educación acortaría los plazos para llegar a la alberdiana república verdadera. Afirmaba que era una falacia pensar que el pueblo no estuviera preparado para la democracia.

\footnotetext{
12 Para una mirada retrospectiva y más distante y cautelosa respecto de la guerra y sus costos, véase ESTRADA 1904 , p. 243-245.

${ }^{13}$ Aunque, como ha sostenido Botana, el Sarmiento de la presidencia se volcó por las ideas de la necesidad de una"república fuerte", Estrada vio durante su mandato al Sarmiento de las virtudes cívicas (BOTANA 1991).

${ }^{14}$ Halperin Donghi presentó este tópico de Estrada deteniéndose en el artículo más tardío, de 1873, sobre el tema (HALPERIN DONGHI 1995). Se recupera aquí el despliegue de algunas ideas que Estrada trató en escritos de 1868, 1869 y 1873.
} 
Solo era necesario "moralizar al pueblo (y) poner a la universalidad de los individuos en la aptitud de ejercitar todos sus deberes" (ESTRADA 1903, p. 88).

Apenas un año más tarde, sumó una resolución económica para encarrilar los males sociales. En ese sentido, elogiaba el programa de colonización agrícola pensado por Sarmiento para ordenar la vida de "nuestros nómades pastores". Si las soluciones indicadas (educación popular y colonización agrícola) no se hacían efectivas a la brevedad, podría tomar forma aquella "ecuación patológica" de la sociedad argentina: "un engendro liberal, más una superfetación de barbarie" (ESTRADA 1903, p. 121).

Poblar no era para Estrada la solución más contundente para erradicar el desorden. Así lo expresó en sus críticas a Juan B. Alberdi en el marco de su comentario de 1875 a Peregrinación de luz del día (ESTRADA 1904). Para gobernar era necesario resolver problemas intrínsecos de la sociedad heredada, ya que, si antes se le sumaban nuevos conflictos, el resultado sería una superposición de tipos sociales que solo generaría más tensiones:

el propietario que aplica a su manera las doctrinas que prevalecen en las instituciones, y que para cultivar eficazmente su propio y directo interés, rechaza al paisano que va a pedirle trabajo [...] busca al extranjero, hecho dueño del país por la imprevisión de nuestras leyes, que lo protege, lo mima, lo enriquece; y mientras el gaucho guerrilea en la frontera y su triste hogar se apaga, el vasco se familiariza con el chiripá y pastorea los rebaños del irlandés adusto, que a su regreso lo recibe con la escopeta bajo el alero del rancho, o de la limosna cuando el aguardiente lo pone expansivo (ESTRADA 1903, p. 113).

Sarmiento y sus proyectos descentralizadores - de educación y colonización- podrían haber encauzado más ajustadamente el proceso de regeneración. Sin embargo, hacia 1873, Estrada regresó a mirar la campaña y una vez más sus reflexiones eran amargas (ESTRADA 1904, p. 60). No se habían atendido las urgencias y la campaña había sido "suprimida del vocabulario político de este país" (ESTRADA 1904, p. 59). Los sucesores de Rosas no habían dado respuestas efectivas a los desequilibrios intrínsecos.

La confianza en los hombres políticos descollantes comenzaba a resultarle a Estrada una opción ociosa y empezó a ser reemplazada gradualmente por una fuerte crítica a los usos que esas figuras hacían de las formas y prácticas democráticas. Estrada vio particularmente a la política de facciones como la responsable de "la inmoralidad cívica" (ESTRADA 1904, p. 291) y la corrupción. Mientras tanto, se profundizaba la centralización de las atribuciones del Estado, que, para Estrada, aislaba cada vez más a la política de la sociedad: "si un pueblo incide en la locura del centralismo, no gozará jamás de las ventajas del gobierno de la sociedad para la sociedad, es decir, de una vida orgánica perfecta" (ESTRADA 1904, p. 294).

Retomando su interés por el régimen municipal, Estrada asumió para mediados de la década de 1870 que la puesta en práctica de programas descentralizadores no solo permitiría una mejor administración del poder y todas sus expresiones, como las judiciales (ESTRADA 1904, p. 102-109), sino también 
una más sana reconfiguración de las estructuras sociales viciadas. Solo si el Estado omitía sus responsabilidades a la hora de propulsar una regeneración social, otras instituciones podían cubrir las demandas insatisfechas (ESTRADA 1904, p. 306).

\section{Las repercusiones de las "lecciones históricas" de Estrada}

Las lecciones e intervenciones históricas de Estrada fueron aclamadas por los hombres de cultura de manera recurrente. Sobre ellas, señaló Groussac que "sin aparato erudito, esta revista de la historia patria contiene más sustancia medular, más enseñanza efectiva que muchas compilaciones ambiciosas e inventarios del pasado" (GROUSSAC 1897, p. 2).

Otros juicios fueron menos halagüeños. Entre ellos, se lee que, en sus Lecciones, "las palabras son más grandes que los personajes, y los párrafos más complicados que los acontecimientos" (CONGRESO DE 1886, p. 121). Por su parte, Rómulo Avedaño escribía en las páginas de La revista de Buenos Aires que el conferencista se había encargado de ensuciar el nombre de prohombres patrios - se refería a la Sociedad Lautaro- mientras "que tuvo bastante calor en defender la figura raquítica y defectuosa de don Santiago de Liniers y Bremont" (AVEDAÑO 1869, p. 441).

Aunque la observación es maliciosa, ya que se juzga a Estrada por reivindicar a su bisabuelo, el virrey Liniers, habilita a una observación interesante acerca de su obra histórica: a lo largo de sus escritos, no tuvo una preferencia por los grandes hombres, sino por los que entendió como emanaciones de fuerzas sociales. De allí su atención por personajes como Fernando Mompo para analizar el levantamiento de los comuneros y, aunque con otro tono, por Rosas.

Luego del éxito de las lecciones de la Escuela Normal, Estrada recibió una designación de Sarmiento para estar al frente de la Cátedra de "Historia Argentina e Instrucción Cívica" en el Colegio Nacional de Buenos Aires. Su performance docente en ese establecimiento fue ampliamente reconocida. Su poder oratorio y su carisma son elementos reiterados en el marco de evocaciones como la que realizó Martín García Mérou:

José Manuel Estrada fomentaba en los alumnos del colegio la inclinación a los estudios literarios. La austeridad de su carácter y de su indiscutible talento inspiraba a todos respeto y simpatía [...] Jamás ha llegado Estrada a un grado más alto de elocuencia arrebatadora que aquella noche inolvidable en que hizo temblar y vibrar como sacudidos por una corriente eléctrica (GARCÍA MÉROU 1973, p. 39-40).

Desde su cátedra del Colegio Nacional de Buenos Aires fue que dictó en 1873 lecciones que se publicaron bajo el título La política liberal bajo la tiranía de Rosas. Se trata de un comentario sobre el Dogma socialista, pero basado en una revisión general de la historia argentina. Al escrito de Echeverría lo considera fruto de la "política militante" (ESTRADA 1917, p. 181) y juzga algunas interpretaciones como erradas. El autor de La política liberal... se muestra capaz dar cuenta de las novedades intelectuales (Tocqueville, Guizot, Taine), de los clásicos (Beccaria, Montesquieu, Rousseau, Kant), así como 
también de las ideas positivistas y cientificistas (menciona a Auguste Comte, Stuart Mill, Charles Darwin, Michel Serres). No duda en afirmar la utilidad de las leyes para entender la sociedad y subraya que "el progreso es la ley de la vida; y el progreso es desarrollo y construcción" (ESTRADA 1917, p. 68-69). De todas formas, manifiesta los límites de esa máxima señalando que las teorías cientificistas son útiles para pensar "al conjunto de la naturaleza, (pero) no a los individuos" (ESTRADA 1917, p. 103).

En la primera lección Estrada sistematiza ideas ya expresadas: "la tiranía de Rosas (fue) la forma de la democracia bárbara en sus degeneraciones naturales y el nudo histórico de la revolución nacional" (ESTRADA 1917, p. 60). Asimismo, presenta una lectura más contundente de la revolución de 1810, a la que considera una "doble revolución": por un lado "obra del pueblo" y, por otro, de una "clase pensadora" (ESTRADA 1917, p. 38). Critica la visión del partido federal y del partido unitario y postula duros juicios sobre la capacidad del "elemento pensador" a la hora de interpretar al "elemento popular" (ESTRADA 1917, p. 46). Esos desdoblamientos se tradujeron en la bifurcación de intenciones y demandas que explicarían los posteriores problemas argentinos.

En la Lectura XI, retoma un tema que ya se subrayó: el valor del municipio como la base de la organización democrática de la sociedad y, en esa dirección, critica ferozmente la supresión de los cabildos de 1821 (ESTRADA 1917, p. 254). ${ }^{15}$ Entiende ese hecho como una oportunidad perdida para organizar la nación en términos realmente democráticos y progresistas (ESTRADA 1917, p. 263). Posteriormente, aborda la cuestión del federalismo y del sistema federal y lamenta, en varias páginas, el error de cálculo que implicó en la historia de la Argentina que los gobiernos nacionales intervinieran constantemente en "los asuntos interiores de las provincias" (ESTRADA 1917, p. 283).

\section{Consideraciones finales}

Rótulos como los de "historiador-orador", "historiador oficial", "educador histórico", "historiósofo" fueron utilizados para pensar el perfil de Estrada como historiador. Alejado de la erudición documental, no ingresó al panteón de los historiadores más reconocidos. La historiografía católica, por su parte, no recuperó al Estrada historiador por diversos motivos: él criticó a la Compañía de Jesús, evaluó en términos peyorativos a España, exaltó la revolución contra la opresión, simpatizó con la guerra civilizadora, coqueteó con la idea de la ley del progreso como ordenadora de la historia e hizo de los Estados Unidos un modelo a la hora de entender las formas de convivencia entre la libertad y la fe. Pese a ello, a juzgar por las opiniones de sus contemporáneos, Estrada fue percibido como una promesa para la cultura nacional y cada una de sus actividades se consideró un aporte a la vida del país.

La trayectoria personal de Estrada, leída en paralelo a sus estudios históricos, muestra una serie de particularidades interesantes en relación con la de varios 
de sus contemporáneos. A diferencia de otras familias patricias de hombres que ocuparon la escena pública en la segunda mitad del siglo XIX, como Héctor Varela, Miguel Cané, Eduardo Wilde, Eduardo Holmberg o Lucio V. López, la familia de Estrada no fue perseguida durante el rosismo ni sufrió la experiencia del exilio. Sin embargo, Estrada es quizás quien legó, tanto en sus Lecciones de historia de la República Argentina como en La política liberal bajo la tiranía de Rosas, las lecturas más críticas sobre el pasado rosista, aunque siempre entendió el fenómeno como resultado de las dinámicas sociales y políticas del país. Ese hecho explica, quizás, su paulatino alejamiento de quien había sido su amigo y guía intelectual en su temprana juventud, Lucio V. Mansilla (quien era, como es sabido, sobrino de Rosas). En sentido inverso, aunque su bisabuelo, el virrey Liniers, fue víctima de la revolución de 1810, Estrada reivindicó los sucesos revolucionarios.

A juzgar por esos indicios, no fueron móviles o deudas familiares los que lo condujeron a pensar el pasado. Sus relatos históricos pueden inscribirse, sin demasiados problemas, en la tradición abocada a narrar la nación y dotarla de una identidad. Varias de las interpretaciones de Estrada coinciden con las de Bartolomé Mitre. Sin embargo -y este es un interesante rasgo de su lectura sobre el pasado-, su interpretación sobre la etapa prerrevolucionaria se distancia de las propuestas por el historiador de Belgrano y San Martín. No encontró en el pasado colonial ningún tipo de preconfiguración de un destino democrático para la Argentina. De hecho, si hubiese que buscar un continuador de la obra de Estrada en lo que respecta a su opinión sobre la sociedad prerrevolucionaria, podría pensarse en el Juan Agustín García de La ciudad indiana.

Por su parte, Estrada pensó el rosismo como parte de la autobiografía de la nación y no como un paréntesis en su devenir, y eso no fue moneda corriente para la época. Lo que lo diferencia de autores que luego se ocuparon del rosismo, como Ernesto Quesada en La época de Rosas y Adolfo Saldías en Historia de la Confederación Argentina: Rosas y su época, es que, para la época en que se propuso pensar el rosismo, los balances sobre este todavía organizaban las pasiones políticas. Pese a ello, su interés por las relaciones entre caudillos y fuerzas sociales y sus preguntas sobre el origen de las tiranías, como es sabido, fueron tópicos que numerosos intelectuales reconsiderarían a la luz de las novedades de las ciencias sociales en las décadas posteriores. El ejemplo obvio es el de Las multitudes argentinas y de Rosas y su tiempo, de José María Ramos Mejía.

Respecto de la lectura negativa sobre la tradición hispánica, la propuesta de Estrada se encuentra bastante cercana a las postuladas por Vicente Fidel López en Historia de la República Argentina: su origen, su revolución y su desarrollo político hasta 1852 y replanteada más tarde por Agustín Álvarez en La transformación de las razas en América. Se puede situar, por su parte, en la vereda opuesta a las claves interpretativas del Francisco Ramos Mejía de El federalismo argentino, sostenedor de una vindicación de la tradición hispano-católica y de la recuperación de España para trazar los orígenes de la nación. Sin embargo la mirada positiva sobre los cabildos como germen y pilar de la organización federal de la Argentina puede acercarlo al mismo Francisco Ramos Mejía. 
Así, pese a que varios de los tópicos expuestos desde mediados de la década de 1860 y comienzos de la década de 1870 en la obra histórica de Estrada estuvieron destinados a ser puntos de interés clásicos, su legado no Ilamó ampliamente la atención a la posteridad. Entre sus pares, por su parte, solo el poco afecto a reconocer guías intelectuales Paul Groussac, refiriéndose al Estrada historiador, lo recordó como "maestro mío en la materia" (GROUSSAC 1919 , p. 5). Es quizás la preferencia por elegir figuras históricas que no encajan en el perfil del gran hombre lo que permite trazar una continuidad entre Estrada y Groussac (BRUNO 2005; 2011). De todas maneras, aunque no fue reconocido como padre fundador de una escuela fructífera, existen indicios para pensar que las Lecciones de historia de la República Argentina tuvieron cierto efecto en la redacción de otros libros destinados a la enseñanza de la historia. ${ }^{16}$

\section{Referencias bibliográficas}

AA.VV. Estrada: centenario de su nacimiento. 1842-13 de julio-1942. Buenos Aires: Libro de Edición Argentina, 1943.

ANUARIO bibliográfico de la República Argentina. Director: Alberto Navarro Viola, a. 2, 1880.

ARCHIVo GeNERAL DE LA NACIÓN. Universidad Católica Argentina, Fondo Manuel Estrada.

AVEDAÑO, Rómulo. La Sociedad Lautaro. Refutaciones históricas, al Señor José Manuel Estrada. La revista de Buenos Aires, t. XIX, p. 129-141, 1869.

BARBANO, Filippo et al. Sociologia, storia, positivismo. Milán: Franco Angeli, 1992.

BOTANA, Natalio. Sarmiento y el orden político: libertad, poder y virtud. In: La libertad política y su historia. Buenos Aires: Sudamericana/ Instituto Torcuato Di Tella, 1991, p. 199-216.

BREZZO, Liliana M. La guerra del Paraguay a través de la memoria de sus actores: el proyecto historiográfico de Estanislao Zeballos. Nuevo Mundo Mundos Nuevos, Coloquios, 2006. Disponible en: http://nuevomundo. revues.org/index1677.html. Consultado el: 30 jun. 2014.

BRUNO, Paula. Pioneros culturales de la Argentina. Biografías de una época. Buenos Aires: Siglo Veintiuno Editores, 2011.

El Círculo Literario, 1864-1865/6: entre la conciliación de intereses y las tensiones de la hora. In: (dir.). Sociabilidades y vida cultural,

Buenos Aires 1960-1930. Buenos Aires: Editorial de la Universidad de Quilmes, 2014, p. 27-58.

\footnotetext{
${ }_{16}$ En este sentido, por ejemplo, véase en el Anuario bibliográfico la reseña de las Lecciones de historia nacional de Agustín Pressinger (catedrático del Colegio Militar de la Nación y del Colegio Nacional de Buenos Aires) publicadas por Imprenta Ostwald en 1880; allí se lee:"El compendio de historia del Sr. Agustín Pressinger difiere fundamentalmente de los compendios que conozco [...] el autor ha tenido que consultar su capacidad general, y ha hecho un trabajo sencillo y claro, [...] pero a la vez de un método que abre vastos y profundos horizontes a la enseñanza de la historia patria, y acusa, aunque el autor no lo confiese, la preferencia que ha dado en sus estudios a las lecciones de D. José Manuel Estrada" (ANUARIO 1880, p. 146).
} 
Paul Groussac: un estratega intelectual. Buenos Aires: Fondo de Cultura Económica, 2005.

CARBIA, Rómulo. Historia crítica de la historiografía argentina. Desde sus orígenes en el siglo XVI. La Plata: Universidad Nacional de La Plata, 1939 [1925].

CLEMENTI, Hebe. Rosas en la Historia Nacional. Buenos Aires: Editorial La Pleyade, 1970.

CONGRESO DE 1886. Siluetas parlamentarias. Buenos Aires: Edición de El Nacional, 1886.

DE GANDÍA, Enrique. Conferencia pronunciada en el Círculo de la Prensa, el 10 de julio de 1942. In: AA.VV. Estrada: centenario de su nacimiento. 184213 de julio-1942. Buenos Aires: Libro de Edición Argentina, 1943.

. La herencia de mayo en Echeverría y Estrada. Boletín de la Academia Nacional de la Historia, t. XXXIII, segunda sección, p. 403-420, 1962.

DE PATAGONES, Carlos. José Manuel Estrada: El hombre-El apologista-El Santo. Buenos Aires: Talleres Gráficos Argentinos L. J. Rosso, 1938.

DEVOTO, Fernando; PAGANO, Nora. Historia de la historiografía argentina. Buenos Aires: Sudamericana, 2009.

ESTRADA, José Manuel. Historia del Paraguay, Río de la Plata y Tucumán por 102 el P. José de Guevara (Don Pedro de Angelis y Don Félix de Azara). La Revista de Buenos Aires: Historia Americana, Literatura y Derecho, t. I, p. 139-141 y 562-572, 1863.

Los PP. Gervasoni y Cattaneo. Carta-introducción. La Revista de Buenos Aires, t. VIII, p. 552-560, 1865.

Obras completas. Tomo II: Lecciones sobre la historia de la República Argentina. Tomo I. Buenos Aires: Librería del Colegio, 1896a.

Obras completas. Tomo III: Lecciones sobre la historia de la República Argentina. Tomo II. Buenos Aires: Librería del Colegio, 1896b.

. Obras completas. Tomo I: El génesis de nuestra raza; El catolicismo y la democracia; Los comuneros del Paraguay. Buenos Aires: Librería del Colegio, 1899 [1865].

- Obras completas. Tomo V: Fragmentos históricos. Buenos Aires: Librería del Colegio, 1901.

. La moral y la democracia. In: Obras completas. Tomo IX:

Miscelánea. Estudios y artículos varios. Tomo I. Buenos Aires: Compañía Sud-Americana de Billetes de Banco, 1903 [1868].

. La campaña. In: Obras completas. Tomo IX: Miscelánea.

Estudios y artículos varios. Tomo I. Buenos Aires, Compañía SudAmericana de Billetes de Banco, 1903 [1869]. 
La Educación Común en la Provincia de Buenos Aires. In:

Obras

completas. Tomo IX: Miscelánea. Estudios y artículos varios. Tomo I.

Buenos Aires, Compañía Sud-Americana de Billetes de Banco, 1903 [1870].

Once de septiembre. In:

Obras completas. Tomo $\mathrm{X}$ :

Miscelánea. Estudios y artículos varios. Tomo II. Buenos Aires, Librería del Colegio, 1904 [1873a].

Una palabra suprimida. La campaña. In:

Obras completas.

Tomo X: Miscelánea. Estudios y artículos varios. Tomo II. Buenos Aires, Librería del Colegio, 1904 [1873b].

. La negociación en el Paraguay. In:

Obras completas. Tomo

X: Miscelánea. Estudios y artículos varios. Tomo II. Buenos Aires, Librería del Colegio, 1904 [1874a].

- Reformas judiciales. In:

Obras completas. Tomo $\mathrm{X}$ :

Miscelánea. Estudios y artículos varios. Tomo II. Buenos Aires, Librería del Colegio, 1904 [1874b].

24 de mayo de 1810. In:

Obras completas. Tomo XI:

Miscelánea. Estudios y artículos varios. Tomo III. Buenos Aires: Compañía

Sud-Americana de Billetes de Banco, 1904 [1874c].

- Peregrinación de Luz del Día. Examen crítico. In:

Obras

completas. Tomo X: Miscelánea. Estudios y artículos varios. Tomo II. Buenos Aires, Librería del Colegio, 1904 [1875], p. 275-329.

. La política liberal bajo la tiranía de Rosas. Buenos Aires: Librería La Facultad, 1917 [1873].

EUJANIAN, Alejandro. El surgimiento de la crítica historiográfica. In: CATTARUZZA, Alejandro; Políticas de la Historia. Argentina 1860-1960.

Buenos Aires: Alianza Editorial, 1999, p. 17-41.

GARCÍA MÉROU, Martín. Recuerdos literarios. Buenos Aires: Eudeba, 1973 [1891].

GARRO, Juan. José Manuel Estrada. Noticia Biográfica. In: ESTRADA, José Manuel. Obras completas. Tomo I: El génesis de nuestra raza; El catolicismo y la democracia; Los comuneros del Paraguay. Buenos Aires: Librería del Colegio, 1899, p. V-CIV.

GOYENA, Pedro. José Manuel Estrada. Crítica Literaria. Buenos Aires: Eudeba, 1965.

GROUSSAC, Paul. Lecciones de Historia de la República Argentina, por José Manuel Estrada. In: Prospecto de las Obras Completas de José Manuel Estrada. Buenos Aires: Librería del Colegio, 1897.

Noticia del padre José Guevara y estudio crítico de la historia del Paraguay. Anales de la Biblioteca Nacional, t. V, 1908, p. VII-X.

. Los que pasaban. Buenos Aires: Jesús Méndez, Librero Editor, 1919. 
HALPERIN DONGHI, Tulio. Proyecto y construcción de una nación (18461880). Buenos Aires: Ariel, 1995.

LINARES QUINTANA, Segundo. The Etiology of Revolutions in Latin America. The Western Political Quarterly, v. 4, n. 2, p. 254-267, 1951.

MARI, Óscar. Las Misiones Jesuíticas en la historiografía argentina entre la segunda mitad del siglo XIX y principios del siglo XX. Revista Complutense de Historia de América, n. 31, p. 101-114, 2005.

MURUA, Pedro Oscar. José Manuel Estrada y la democracia liberal. Universidad, Publicación de la Universidad Nacional del Litoral, Separata, 1942.

ORGAZ, Raúl. Ensayos históricos y filosóficos. Córdoba: Assandri, 1960.

PAGANO, Nora; GALANTE, Miguel. La Nueva Escuela Histórica: una aproximación institucional del centenario a la década del 40. In: DEVOTO, Fernando (comp.). La historiografía argentina en el siglo XX (I). Buenos Aires: Centro Editor de América Latina, 1993, p. 45-78.

PRADO, Gustavo. Las condiciones de existencia de la historiografía decimonónica argentina. In: DEVOTO, Fernando. Estudios de historiografía argentina (II). Buenos Aires: Editorial Biblos, 1999, p. 37-74.

QUATTROCCHI-WOISSON, Diana. Los males de la memoria. Historia y política en la Argentina. Buenos Aires: Emecé, 1998.

QUESADA, Vicente. Bibliografía y variedades. Bosquejo histórico de la civilización política en las provincias del Río de la Plata (Conferencias públicas) por Don José Manuel Estrada. Noticia de estas conferencias. La Revista de Buenos Aires, t. IX, p. 135-137, 1866.

SCENNA, Miguel. Los que escribieron nuestra historia. Todo es Historia, n. 65, p. 66-92, 1972.

TERNAVASIO, Marcela. ¿Política municipal o municipios apolíticos? Un debate en la Revista Argentina de Ciencias Políticas. In: ROLDÁN, Darío (comp.). Crear la democracia: la Revista Argentina de Ciencias Políticas y el debate en torno de la república verdadera. Buenos Aires: Fondo de Cultura Económica, 2006, p. 137-186.

TESSI, Francisco. Vida y obra de José Manuel Estrada. Buenos Aires: Talleres de Jacobo Peuser, 1928.

WASSERMAN, Fabio. Conocimiento histórico y representaciones del pasado en el Río de la Plata (1830-1860), 345 p. Defendida en 2004. Tesis (Doctorado en Historia). Facultad de Filosofía y Letras, Universidad de Buenos Aires, 2004.

. Entre Clio y la Polis: conocimiento histórico y representaciones del pasado en el Río de la Plata (1830-1960). Buenos Aires: Teseo, 2008.

ZULUAGA, Rosa. El primer ensayo de una filosofía de la historia nacional. Las lecciones de José Manuel Estrada, 1866-1868. Revista de Historia Americana y Argentina, Mendoza, n. 5-6, p. 237-298, 1960-1961. 